\title{
Analysis for Underwater Sound on Natural River Habitat
}

\author{
Jung-Eun Gu ${ }^{1}$, Sang Hwa Jung ${ }^{1}$, Joongu Kang ${ }^{1}$, Hyoseop Woo $^{2}$ \\ ${ }^{1}$ Korea Institute of Civil Engineering and Building Technology, Goyang-si, Gyeonggi-do, 10223, \\ Republic of Korea \\ ${ }^{2}$ Gwangju Institute of Science and Technology, Buk-gu, Gwangju,,61005, Republic of Korea
}

\begin{abstract}
A riffle-pool structure is a representative physical structure of bed in rivers. The change in the physical parameter of the habitat could lead to changes in the sound environment of rivers, which are expressed by underwater acoustics. This change in underwater sound affects fish habitat. In this study, the changes of underwater acoustics were analyzed according to the change of pool-riffle sequence in a natural river. And the correlation between underwater acoustics and hydraulic characteristics was investigated. The survey for underwater acoustics was performed in the Namdae stream where is in Gangwon province. This stream belongs to the Han River basin and the river length is $39.01 \mathrm{~km}$ and the catchment area is $127.56 \mathrm{~km}^{2}$. The Namdae stream is a river that accounts for more than $70 \%$ of salmon returning to South Korea. The spawning salmon will return to this area around November after growing in the Bering Sea. It is important to manage the fish habitat in this river so there is a lot of research on the enhancement of fish habitat. Hydraulic characteristics were changed by the river bed structure. In this study, we investigated the relationship between underwater acoustic characteristics and hydraulic factors such as riverbed material, flow rate and water depth of each habitat type at 12 sites. The characteristics of underwater acoustic differed relative to different hydraulic factors of the two habitats, which is riffle and pool. The sound pressure level of riffles was relatively higher than that of the pools due to bed materials, shallow depth and high water velocity of riffles. In the future, it is considered that the underwater sound can be utilized as a parameter to evaluate the physical habitat environment of the river.
\end{abstract}

\section{Introduction}

The diversity and community structure of fish are significantly influenced by physical characteristics, such as river depth and velocity, riverbed slope, riverbed material, and vegetation, etc. (Gorman et al., 1978; Poff et al. al., 1995). These characteristics distinguish the type of habitat, which can be divided into various types such as a 'pool' with deep depth and low velocity, a 'riffle' with a shallow depth and high velocity, and a 'step pool' with a fall. Recently, many studies have been attempted because certain physical sounds recorded below the water surface act as potential indicators of the habitat soundscape. According to Tonolla et al. (2009), due to geographical differences of rivers, the water flow is disturbed and sound is generated by velocity, flow rate, and bubbles, and the underwater sound pressure 
is increased according to the velocity. Amoser et al. (2011) studied the underwater acoustics of flowing waters such as rivers and standing waters such as lakes. Underwater acoustics is characterized by a combination of water flow, transfer of riverbed material, wind, animal sounds, and artificial sounds of each water body. As such, the underwater acoustics of a river is highly influenced by the underwater, the surrounding environment, and the physical characteristics of the river, which suggest the possibility of their application as a new method for evaluating river environment. Underwater acoustics is caused by sound waves, which are pressure disturbances transmitted through water. Although they are not critical to terrestrial organisms, sound waves play a significant role as a means of transporting a large amount of information to aquatic animals (Popper et al., 1998In this study, Namdaecheon Stream, which is located in Yangyang was selected as the target of our research subject because of the following attributes: deep valley composition, presence of many tributaries, rich flow rate, and one of the representative natural channels with little artificial noise that may interfere with the measurement.

The purpose of this study is to investigate the relationship between underwater acoustics and hydraulic characteristics, such as velocity, depth of water, and riverbed material, etc. according to the riffles, pools, and step pools of Namdaecheon Stream. Also it is to compare the sound pressure level according to the habitat types that it may be used as means for evaluation the physical characteristics of biological habitats.

\section{Research Method and Research Target River}

\subsection{Target River and Research Method}

To analyze the acoustic characteristics of a natural river, Namdaecheon Stream, Yangyang was selected as the target location because the natural environment is relatively well preserved. Namdaecheon Stream, Yangyang has a river length of $54.0 \mathrm{~km}$ and a basin area of $474.8 \mathrm{~km}^{2}$. The largest basin area is in the Yeongdong area, and the stream originates from the eastern valley of Durobong (1,422 m) in Samsan-ri, Yeongok-myeon, Gangneung-si. It joins Hucheon Stream in Yangyang-eup, and flows northeast into the East Sea. The upper stream of Namdae Stream, Yangyang is the measurement point and it meanders greatly, displaying the characteristics of a meandering river composed of riffles and pools.

The underwater acoustics of the natural river and the physical characteristics of the habitat were measured upstream of Namdaecheon Stream, Yangyang and the measurement period was from June 26-30 to avoid the rainy season. The weather was clear at the time of measurement, with higher flow rates than the dry season and lower flow rates than the rainy season. The average temperature during the measurement period was between $20{ }^{\circ} \mathrm{C}$ and $25{ }^{\circ} \mathrm{C}$, with the daytime high of $31.4{ }^{\circ} \mathrm{C}$ and the lowest temperature of $16.6^{\circ} \mathrm{C}$. Each measurement point was measured sequentially from $\mathrm{H} 1$ to $\mathrm{H} 12$, and the measurement time was in the morning when the temperature was gradually rising. Therefore, the water temperature also gradually increased from 21.0 to 23.7 as it moved from H1 to H12. The research target section for this study is the mountain stream connected to Beopsuchi Valley where it meanders greatly and shows the characteristics of a meandering river. The riverbed structure of this section was observed visually with a ruler on site, in accordance with the sand particle size classification by Woo et al. (2015). The riverbed materials are composed of mainly coarse-grained boulders that vary in size, from very large (4096 mm $2048 \mathrm{~mm}$ ), large $(2048 \mathrm{~mm} \sim 1024 \mathrm{~mm})$, medium $(1024 \mathrm{~mm} \sim 512 \mathrm{~mm})$, and small $(512 \mathrm{~mm} \sim 256$ $\mathrm{mm})$. The riverbed materials also comprise cobbles that are both large $(256 \mathrm{~mm} \sim 128 \mathrm{~mm})$ 
and small $(128 \mathrm{~mm} \sim 64 \mathrm{~mm})$ in size. Pebbles and sand were hard to find on the riverbed of the target location.

A total of 12 measurement points were selected near Hapsil Bridge at the upstream of Namdaecheon Stream, Yangyang as shown in Fig. 1. The horizontal distance of each section was measured at intervals while moving from upstream to downstream. Measurement points were mainly composed of riverbed material, such as boulders of various sizes (very large, large, medium, small) as well as large and small cobbles, etc. The point where it was difficult to take a photograph (H7) was substituted to a point similar to the measurement point. The target river is mostly composed of riffles and pools, though step pools are included in some areas as well.

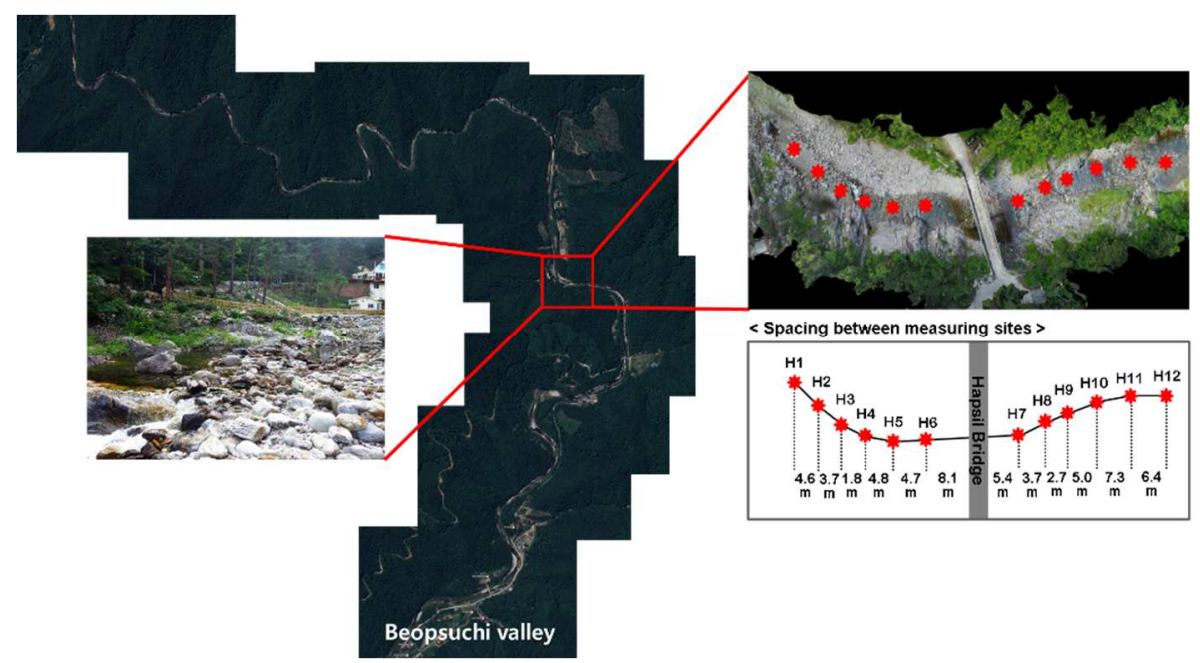

Fig. 1. Location of the 12 measurement points in Namdaecheon Stream, Yangyang.

\subsection{Sound Measurement and Analysis}

Underwater acoustics can be measured from $5 \mathrm{~Hz}$ to $120 \mathrm{kHz}$, and the Hydrophone (TS-4032, Prosig) and Prosig P8004 system with $-170 \mathrm{~dB}$ re $1 \mathrm{~V} / \mathrm{mPa}$ receiver sensitivity was used in the measurement. The underwater acoustics at each point were measured while moving from upstream to downstream by placing the Hydrophone at the middle of the river bottom at each point. The measurement was repeated five times for 60 seconds each. As the measurement points of Namdaecheon Stream, Yangyang are desolate areas, it is possible during recordings to exclude the artificial noise from the surroundings other than the sounds of the river and nature. The underwater acoustics measured was analyzed using a DATs Analysis program.

The Sound Pressure Level (SPL) according to the frequency was analyzed in order to evaluate the underwater acoustics of each point. For the analysis, the acoustic signal was calculated as the Root Mean Square (RMS). SPL represents the energy over the measured frequency range, and the effective magnitude of the sound is defined by the following equation (1) using waveform $X(t)$ and measurement time width $T$. 


$$
\mathrm{SPL}=\left[\frac{1}{T} \int_{0}^{T} X^{2}(t) d t\right]^{0.5}
$$

As human audible frequencies range from 20 to $20,000 \mathrm{~Hz}$, the use of $1 \mathrm{~Hz}$ resolution will be different from what human beings perceive. Therefore, the octave band analysis method is often used as a similar means of expression that is compatible with human ears. In this study, we used 1/3-octave band for analysis.

Equivalent Noise Level is a value used for environmental noise measurements and is expressed by using the mean of the noise that varies during the selected time, or with the square root of the mean. Equivalent Noise Level (Leq) is used to compare the degree of underwater background sound according to the habitat and is defined by the following equation (2). T stands for the measurement time, $\mathrm{P}(\mathrm{t})$ is the sound pressure of the changing noise, and $\mathrm{P}_{0}$ is the underwater reference sound pressure at $1 \mu \mathrm{Pa}$. The background sound of each habitat was compared using an average of the five repeated measurements of equivalent noise levels measured for 60 seconds.

$$
L_{e q}=10 \log _{10} \frac{1}{T} \int_{0}^{T}\left(\frac{p(t)}{P_{0}}\right)^{2} d t
$$

\section{Results and Observation}

\subsection{Physical Characteristics of the Target River}

Water depth, water temperature, velocity, and riverbed material were measured to understand the physical characteristics of the target river. The measurement point is connected to Beopsuchi Valley, where the pool depth is $0.73 \mathrm{~m} \sim 0.92 \mathrm{~m}$ and the velocity is $0.01 \mathrm{~ms}^{-1} \sim$ $0.36 \mathrm{~ms}^{-1}$, and the depth of the riffle is $0.07 \mathrm{~m} \sim 0.39 \mathrm{~m}$ and the velocity is $0.53 \mathrm{~ms}^{-1} \sim 0.96$ $\mathrm{ms}^{-1}$. Points H3, H6, H7, H8, and $\mathrm{H} 12$ are pools with deep waters and a low velocity, whereas points $\mathrm{H} 2, \mathrm{H} 4, \mathrm{H} 5, \mathrm{H} 9$, and $\mathrm{H} 10$ are riffles with lower depths and a high velocity. In addition, the step pool at point H1 had a low depth and low velocity, while point H11 had a low depth and high velocity, which were not characteristic of the habitat.

\subsection{Underwater Acoustic Characteristics}

The sound from the river can be divided into abiotic and biotic factors (Amoser et al., 2005). Abiotic factors include the sound of water flow, the sound of contact with the riverbed material, and the sound transmitted from the atmosphere to the water. Biological factors include the movement or vocalization of aquatic organisms or the sound transmitted by organisms in the atmosphere. The underwater acoustics analysis according to the habitat was conducted under these considerations. The measurement point was connected to Beopsuchi Valley, Namdaecheon Stream, Yangyang, and the water depth was generally shallow and clear, allowing for the condition in which marsh snails could be found in the upstream. Fish were occasionally observed in the downstream pool, which was a non-measurement point. However, almost no organisms such as fish were found at the measurement point, so there was almost no impact from living organisms. Therefore, most of the sound was attributed to abiotic factors and based on this, the underwater acoustics were formed by the influences of velocity, riverbed material, and water depth. 


\subsubsection{Riffle}

Among the measurement points, $\mathrm{H} 2, \mathrm{H} 4, \mathrm{H} 5, \mathrm{H} 9$, and $\mathrm{H} 10$ have the shape of a riffle as a habitat and their respective sound distributions are shown in Fig. 2. The sound pressure at point $\mathrm{H} 2$ steadily decreased from a high value of about $146 \mathrm{~dB}$ re $1 \mu \mathrm{Pa}$ at low frequencies. They then increased again at $160 \mathrm{~Hz}$ and tended to decrease again at 1,250 Hz. Point H5 showed a generally lower sound pressure level than the point $\mathrm{H} 2$, and showed a higher sound pressure than $\mathrm{H} 2$ at $20 \mathrm{~Hz}$, at $80 \mathrm{~Hz}$, and above 4,000 Hz. As shown in Fig. 2, the sound pressure level is significantly affected by the velocity, and the underwater acoustics can vary with the riverbed materials. The riverbed materials of these points are mainly boulders of various sizes (very large, large, small), most likely resulting from the friction of water flow and riverbed materials.

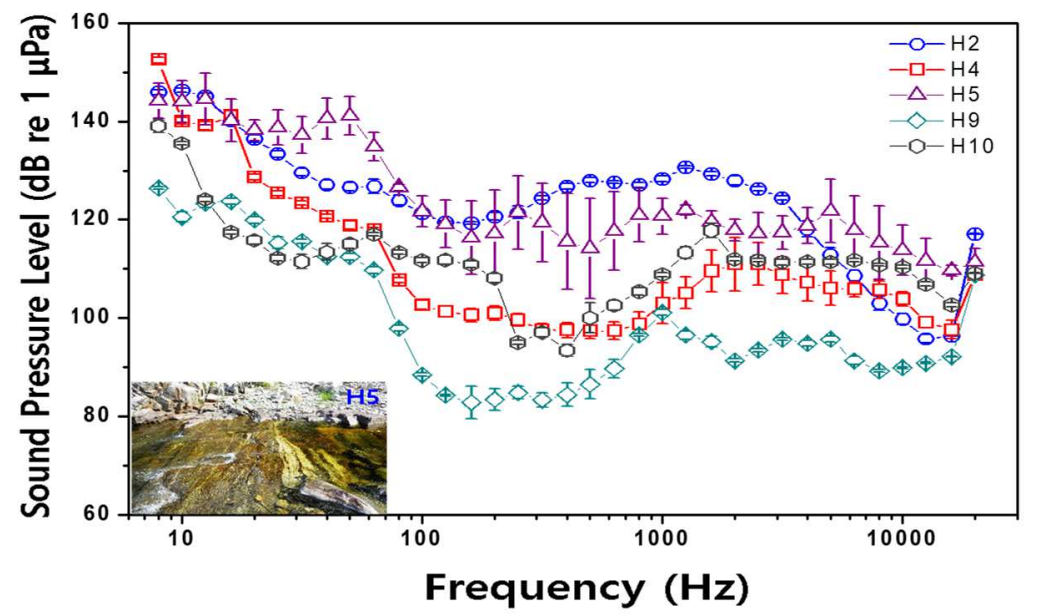

Fig. 2. Underwater acoustic characteristics of $1 / 3$ octave bands in riffle

\subsubsection{Pool}

Points H3, H6, H7, H8, and H12 are pool-type habitats with characteristics of low velocity and deep water depth. The underwater acoustic characteristics of these points show high sound pressure levels at point $\mathrm{H} 3$ and $\mathrm{H} 6$ in the low-frequency range, while point $\mathrm{H} 7, \mathrm{H} 8$, and $\mathrm{H} 12$ show low sound pressure levels (Fig.3). Even the same types of habitat show different underwater acoustic characteristics, so various factors need to be considered. Various physical factors, such as roughness of the riverbed material, width of the river, flow characteristics, etc. create the underwater environment, which in turn changes the characteristics of underwater acoustics (Amoser et al., 2011).

Points H3 and H6 showed high sound pressure levels of $129 \mathrm{~dB}$ re $1 \mu \mathrm{Pa}$ and $124 \mathrm{~dB}$ re $1 \mu \mathrm{Pa}$, respectively from $31.5 \mathrm{~Hz} \sim 40 \mathrm{~Hz}$, but beyond that, the levels decreased rapidly and increased again at $100 \mathrm{~Hz}$ and $250 \mathrm{~Hz}$, respectively. Characteristic peaks appeared at $800 \mathrm{~Hz}$ and $630 \mathrm{~Hz}$ and decreased again in the high-frequency region. The low-frequency range of underwater acoustics that affects living organisms in rivers and streams travel very little in shallow water because the wavelength is greater than the depth (Atema et al., 1988). Lowfrequency sound weakens at a faster rate as it moves away from the sound source in shallow water than in the deep water. It is observed that the deeper the water, the more gradual the low frequency sound can be delivered. On rocky riverbeds, the lowest frequency that travels in $1 \mathrm{~m}$ deep water is approximately $300 \mathrm{~Hz}$ (Popper et al., 1998). If the depth is $10 \mathrm{~m}$, the 
lowest transmission frequency is approximately $30 \mathrm{~Hz}$. Therefore, it is considered that the sound pressure level of low frequencies is high in the pools with low velocity. Because lowfrequency progression is strongly influenced by depth, fish in shallow habitats can sense lower frequency sounds (Popper et al., 1998). Lower frequency sounds tend to be very similar at frequencies below $160 \mathrm{~Hz}$ and above $1000 \mathrm{~Hz}$. It is considered that the underwater acoustic characteristics from the original pool appear because the frequency sound transmitted from the similar physical environment and upstream is minimized.

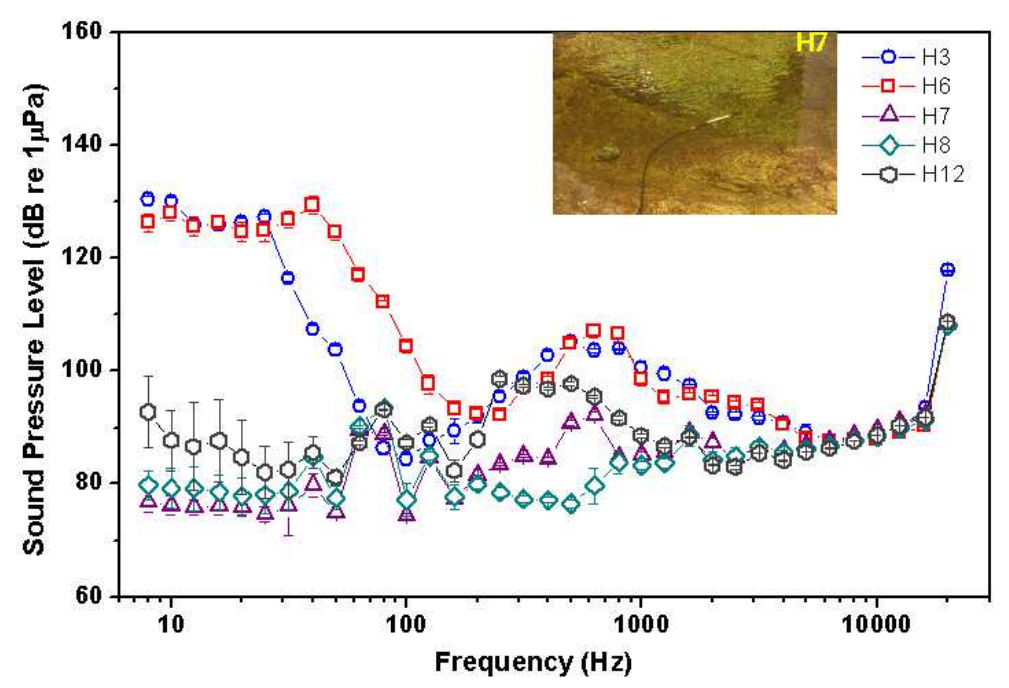

Fig. 3. Underwater acoustic characteristics of $1 / 3$ octave bands in pool

\subsubsection{Comparison of Underwater Acoustics by Habitat Type}

The habitat types of the research target can be divided into riffles and pools, and the acoustic characteristics of each site are shown above. Comparing the average sound pressure level by habitat type, riffles showed higher sound pressure levels than pools. On average, pools showed low sound pressure levels, and riffles showed a characteristic peak with high sound pressure levels below $100 \mathrm{~Hz}$, and pools showed low sound pressure levels below $100 \mathrm{~dB}$ re $1 \mu \mathrm{Pa}$ at $100 \mathrm{~Hz}$ or higher $(101 \mathrm{~dB}$ re $1 \mu \mathrm{Pa}$ at $630 \mathrm{~Hz})$, respectively.

\section{Conclusion}

In this study, the underwater acoustic characteristics according to the habitat were analyzed by using the hydraulic characteristics of the research target to divide and evaluate the pools, riffles, and the step pools. A total of 12 measurement points upstream of Namdaecheon Stream, Yangyang were selected, where habitat types were classified and hydraulic characteristics, such as velocity, depth, and riverbed material, and underwater acoustic characteristics were compared. In the case of riffles, similar acoustic characteristics were observed as the sound pressure level decreased to $160 \mathrm{~Hz}$ and then increased again. In the case of pools, the sound pressure level was generally lower than $100 \mathrm{~dB}$ re $1 \mu \mathrm{Pa}$, although it showed slight fluctuation up to $100 \mathrm{~Hz}$. 
There are very limited environments aquatic organisms can inhabit under various physical conditions of rivers. Therefore, efforts are currently underway to preserve or restore biological habitats through such projects as the ecological restoration of rivers. As part of this effort, evaluation techniques for classifying habitats as suitable for living organisms are also being actively discussed and attempted. The objective of this study was to understand the relationship between underwater acoustics and the hydraulic characteristics of habitats as a measure for evaluating biological habitats, and to propose underwater acoustic measurement as a new method to evaluate biological habitats through various characteristics of habitat types and hydraulic conditions. From the research, it was concluded that underwater acoustics exhibit various characteristics according to the habitat type and hydraulic condition, and further studies are needed in the future.

\section{Acknowledgements}

This research was supported by a grant(18TBIP-C112926-03) from Technology Business Innovation Program founded by Ministry of Land, Infrastructure and Transport of Korean government and also supported by the National Research Foundation of Korea (NRF) grant founded by the Korea government (MSIP)(No.2017R1A2B4007131).

\section{References}

1. A.N. Popper, T.J. Carlson, Trans. Am. Fish. Soc., 127, 5 (1998)

2. D. Tonolla, M.S. Lorang, K. Heutschi, K. Tockner, Aquat. Sci., 71, 4 (2009)

3. H.S. Woo, W. Kim, W. Ji, River Hydraulics (Cheongmungag, Paju, 2015)

4. J. Atema, R.R. Fay, A. N. Popper, W.N. Tavolga, Sensory Biology of Aquatic Animals (Springer-Verlag, New York, 1988)

5. N.L. Poff, J.D. Allan, Ecology, 76, 2 (1995)

6. O.T. Gorman, J.R. Karr, Ecology, 59, 3 (1978)

7. S. Amorser, F. Ladich, Aquat. Sci., 72, 3 (2011)

8. S. Amorser, F. Ladich, J. Exp. Biol., 208 (2005) 